\title{
La sociabilidad epistolar en las prácticas de naturalistas amateurs: el caso del uruguayo Mariano B. Berro $(1838-1919)^{*}$
}

\author{
por \\ Susana V. García ${ }^{1}$ \\ CONICET / Museo de La Plata, Argentina
}

\begin{abstract}
Este trabajo examina algunas cuestiones vinculadas a las actividades de naturalistas amateurs en Sudamérica, focalizándose en la correspondencia y las prácticas botánicas de Mariano Balbino Berro, un hacendado uruguayo devenido en «entusiasta aficionado» por el estudio de la naturaleza local. Este caso ilustra la dinámica de las redes de circulación de muestras e información entre aficionados y especialistas de Sudamérica y Europa en la transición del siglo XIX al XX.
\end{abstract}

Palabras Clave: aficionados; botánica; Uruguay; Argentina; redes epistolares.

Cómo Citar Este Artículo / Citation: García, Susana V., "La sociabilidad epistolar en las prácticas de naturalistas amateurs: el caso del uruguayo Mariano B. Berro (1838-1919)", Revista de Indias, LXXXI/282 (Madrid, 2021): 437-565. https://doi.org/10.3989/revindias.2021.016.

* Este trabajo formó parte del proyecto de cooperación internacional ECOS-SUD: «Ciencia ciudadana: los espacios de los aficionados en la práctica de la ciencia, 1850-1950», dirigido por Irina Podgorny y Nathalie Richard y financiado por el Programa de Cooperación del Ministerio de Ciencia, Tecnología e Innovación de la Argentina y ECOS de Francia. También contó con recursos de los proyectos de investigación: PIP 0153 y PICT 2015-3534, financiados respectivamente por el Consejo Nacional de Investigaciones Científicas y Técnicas (CONICET) y la Agencia Nacional de Promoción de la Investigación, el Desarrollo Tecnológico y la Innovación de la Argentina.

1 garcia_su@yahoo.com.ar, ORCID iD: https://orcid.org/0000-0001-5151-9230 de uso y distribución Creative Commons Reconocimiento 4.0 Internacional (CC BY 4.0). 
Diversos trabajos de historia de la ciencia han mostrado el papel de los aficionados y otras personas con variada formación e intereses en las prácticas de las ciencias en diferentes momentos y contextos. Algunos de ellos, especialmente aquellos que focalizan en el lado transnacional, cooperativo y asociacionista de las ciencias, han destacado que lejos de la concepción tradicional que vincula la práctica de la ciencia con determinados centros, es pertinente pensar la misma en función de los distintos agentes y espacios involucrados en su desarrollo ${ }^{2}$. Eso ha implicado, entre otras cosas, reconocer que tras importantes figuras e instituciones científicas se esconde un amplio espectro de practicantes menos eminentes y de proveedores de datos, dibujos y objetos ${ }^{3}$, quienes también actuaron como interlocutores y fuente de estímulo y consumo de las investigaciones científicas. Por distintas vías, estas personas participaron en la producción de un conocimiento colectivo, que contribuye de forma indisociable al desarrollo y mantenimiento de una sociabilidad entre aquellos que comparten un interés por los mismos objetos. De hecho, es muy raro que el amateur practique su afición por la ciencia sin dialogar con otros interesados en los mismos objetos o temáticas. Al contrario, lo más frecuente es que comparta su pasión en el seno de una red de contactos o de una asociación, manteniendo intercambios periódicos con sus pares, pero también con especialistas, sobre sus descubrimientos, observaciones o muestras reunidas, para asegurarse de que sus interpretaciones y determinaciones están bien fundadas ${ }^{4}$.

En las llamadas «ciencias de campo», los aficionados y otros colaboradores locales han tenido un papel significativo y de largo aliento en las investigaciones científicas, ya sea remitiendo especímenes comunes de la zona, copilando o mandado informes y observaciones de los pobladores nativos, detectando especies raras de plantas o animales, minerales, fósiles o restos arqueológicos y apoyando de distinta manera el trabajo de «campo» y de gabinete de los científicos profesionales y de otros aficionados ${ }^{5}$. Sus colecciones, además, pueden constituirse en una referencia local para los naturalistas de otras regiones. Por otro lado, a diferencia del naturalista viajero en misión

2 Véase Roberts, 2009: 9-30. Schaffer, Roberts, Raj y Delbourgo, 2009. Klemun, 2012.

3 Véase Corsi, 1988. Desde la década de 1990 se han generado diversos trabajos sobre los colaboradores y las redes de provisión de objetos y datos de destacadas figuras de la historia natural como Linneo, Darwin, Cuvier, entre otros, cuya citación excede la extensión de este artículo.

${ }^{4}$ Varios trabajos han señalado la sociabilidad generada alrededor de la práctica amateur en diferentes disciplinas científicas, véase entre otros: Stebbins, 1980: 34-48. Keeney, 1992. Secord, 1994: 383-408. Charvolin Micoud y Nyhart, 2007. Pupio, 2013: 24-33.

${ }^{5}$ Kohler, 2007: 428-454. 
científica para una institución, los aficionados o quienes trabajan con las cosas de la naturaleza disponen de una experiencia cotidiana y prolongada en la localidad y pueden percibir los cambios estacionales en los organismos y el ambiente así como diferenciar entre las especies comunes o raras en la zona, entre otras observaciones. En ese sentido, administradores rurales, jardineros, boticarios, artesanos, curanderos y otros expertos locales en plantas fueron importantes mediadores en el conocimiento botánico durante el siglo XIX. No obstante, las especificidades de los sistemas de clasificación científica y el uso de los nombres latinos de las plantas generaron problemas a los aficionados no familiarizados con ese vocabulario técnico y las constantes actualizaciones taxonómicas, limitando frecuentemente sus prácticas a las excursiones, la formación de colecciones y los envíos de ejemplares y observaciones a «sabios botánicos» a cambio de la clasificación científica de sus especímenes. Estos intercambios generaron un espectro de relaciones que abarcaron desde vínculos de amistad hasta complejas negociaciones y enemistades, por los tiempos de trabajo, los nombres de las nuevas especies, el reconocimiento a la labor del colector y el estatus del conocimiento local, entre otros asuntos que quedaron registrados en las relaciones epistolares.

Este trabajo trata algunas de estas cuestiones vinculadas a las actividades de botánicos amateurs y las redes de intercambio científico que se desarrollaron desde el espacio sudamericano. Para ello se focaliza en las prácticas naturalistas y las relaciones epistolares de Mariano Balbino Berro (1838-1919), un estanciero uruguayo devenido en un «entusiasta aficionado» por el estudio de la naturaleza en la transición del siglo XIX al XX. El archivo personal de este coleccionista conforma un conjunto documental interesante para examinar la actuación de un botánico aficionado en el cono sur sudamericano y las redes de contactos y circulación de muestras e información entre aficionados y especialistas de Sudamérica y Europa. Sus apuntes y correspondencia enviada y recibida conservada en el Archivo General de la Nación en Montevideo permite analizar varios aspectos ligados a las prácticas de formación de herbarios, el comercio de la historia natural y los circuitos de intercambios de ejemplares, folletos, manuscritos y observaciones así como la sociabilidad epistolar generada alrededor de esas transacciones. Como se intentan mostrar en este trabajo, reconstruir la historia de los naturalistas aficionados a partir de este tipo de fuentes inéditas constituye una vía de acceder a aspectos subjetivos del trabajo científico amateur, a sus prácticas manuscritas y las dinámicas de las relaciones científicas. 
Un «YUYero» en el Plata y su archivo

\begin{abstract}
No soy un botánico, sino un entusiasta aficionado, que me he dedicado à coleccionar las gramíneas que nacen y se crian espontaneamente en este departamento de Soriano, algunas de las cuales tengo sometidas à cultivo, con el fin de escribir una obra apreciándolas según sus condiciones forrajeras, sobre lo cual tengo tomadas ya muchas notas. (...). He pensado que Ud. podría tener interés en recibir un ejemplar de cada especie que poseo, pues podría haber algunas que no hubiese en su herbario, y por su parte dejaría librado à su bondad que cediese aquellos ejemplares..., que yo no poseo. Como Ud. no me conoce debo darle garantía de mi formalidad, y esta se la podría dar el Cónsul oriental ${ }^{6}$.
\end{abstract}

En 1895, el estanciero y coleccionista uruguayo Mariano Balbino Berro se presentaba con estas palabras ante botánicos de la Argentina, ofreciendo intercambiar ejemplares de la región de su estancia, en el oeste de la República del Uruguay. Siguiendo los protocolos epistolares ante nuevos contactos, mencionaba a cónsules, naturalistas u otros conocidos del país vecino que podían respaldar su reputación e interés por la ciencia. Por entonces, Berro tenía 57 años y un año antes había comenzado a formar un herbario y a pensar en dedicarse a las ciencias naturales como una ocupación para sus últimos años de vida y que llenara su tiempo libre al retirarse de la administración de sus campos. Consciente de que no tenía ni formación ni título académico y se había consagrado tardíamente a la ciencia, se autodefinía como «aficionado» o también como un simple «yuyero» o «juntador de yuyos» frente a naturalistas del país vecino y luego de Europa. No obstante, fue considerado un interlocutor válido para discutir «novedades botánicas», mientras sus observaciones y ejemplares fueron incluidos en los catálogos de diversas familias de plantas ${ }^{7}$. Su apellido fue incorporado en los nombres científicos de un género (Berroa) ${ }^{8}$ y de varias especies nuevas para la ciencia, como reconocimiento por su colaboración. Este coleccionista mantuvo una amplia correspondencia e intercambios con varios naturalistas e interesados en plantas de Sudamérica y con los principales especialistas europeos en determinados grupos botánicos (ver listado en el Anexo). Sus actividades como coleccionista, no se restringieron solo a la botánica, sino también abarcaron documentos y

${ }^{6}$ Carta de Mariano Berro a Carlos Spegazzini, 2 de septiembre de 1895, Archivo General de la Nación, Uruguay (AGNU), Colecciones Particulares: Archivo de Mariano B. Berro, caja 81, carpeta 9 .

7 Véase Osorio, 1981: 393- 396. Malme, 1911: 268-274.

${ }^{8}$ En 1913, el botánico suizo Gustave Beauverd creó el género Berroa, que contiene una única especie Berroa gnaphalioides, sobre la base de los ejemplares remitidos por Mariano Berro. Beauverd, 1913: 210. 
libros de la época colonial y en menor medida ejemplares zoológicos, fósiles, piezas arqueológicas e históricas, un interés compartido por otros miembros de su familia y también por estancieros residentes en la región de Soriano.

El apellido Berro remite a una familia extensa y acomodada del Uruguay, descendiente de comerciantes españoles radicados en la época colonial y vinculada a la política, las letras, la historia natural y las actividades agropecuarias del siglo XIX. Hijo de Bernardo Prudencio Berro Larrañaga y Práxedes Bustamante del Puerto, Mariano nació el 8 de diciembre de 1838 en la localidad de Minas y su infancia transcurrió en las quintas familiares ${ }^{9}$. Entre ellas vivió un tiempo en la chacra de Miguelete, donde se conservaban colecciones, acuarelas y manuscritos de su tío abuelo, el naturalista y presbítero Dámaso A. Larrañaga ${ }^{10}$. Varias décadas después, Mariano Berro recordaría que esas colecciones le despertaron a los trece años un interés por las ciencias naturales, el cual fue posteriormente cohibido por las guerras civiles y los acontecimientos políticos de su país ${ }^{11}$. Su padre, Bernardo Berro, también se había interesado por las ciencias naturales en su juventud ${ }^{12}$, colaborando con su tío Larrañaga, para luego dedicarse a la actividad política, llegando a ser presidente del Uruguay entre 1860 y 1864.

Mariano Berro, siguiendo los pasos de su padre, desempeñó cargos en la administración pública y en el ejército, ligado al Partido Nacional ${ }^{13}$. Fue oficial segundo del Ministerio de Hacienda en 1858, subteniente de la Guardia nacional de la capital, oficial primero de la Jefatura Política y de Policía de

\footnotetext{
${ }^{9}$ Villegas Suarez, 1975: XX.
}

10 Dámaso Larrañaga formó parte de un grupo de clérigos ilustrados de la región del Plata interesados en la historia natural y la creación de museos y bibliotecas. Di Stefano, 2010: 259-280. Sobre la actividad científica de Larrañaga y sus redes de contactos, véase: Lopes y Heizer, 2011: 11-23.

${ }^{11}$ Larrañaga vivió en la finca de Miguelete entre 1843 y su muerte en 1848. Su sobrino nieto residió ahí entre 1852 y 1853 y copió algunos manuscritos, como las fábulas que publicaría en 1919 y los procedimientos para mediciones meteorológicas, los cuales trató de implementar sin éxito muchos años después. En una carta al Director del Museo Pedagógico de Montevideo, Berro recordaba la labor naturalista de su tío abuelo y las colecciones que vio en aquella finca: «estaban aún en las piezas altas, sus libros colocados en amplias estanterías, en armarios los objetos de historia natural, papeles è instrumentos, en los cajones las pinturas y lápices de colores, en baúles los pliegos conteniendo las plantas disecadas, etc. Todas estas cosas eran propias para interesar la atención de un muchacho, de 13 años, con marcada inclinación al estudio de las ciencias naturales, de cuyo impulso me apartó siempre la interminable cadena de los sucesos políticos», Carta de Mariano Berro a Alberto Gómez Ruano, 2 de diciembre de 1912, AGNU, Colecciones Particulares: Archivo de Mariano B. Berro, caja 79, carpeta 8.

12 Podgorny, 2011: 29-77.

13 Nombramientos oficiales. Destinos públicos. Comisiones, AGNU, Colecciones Particulares: Archivo de Mariano B. Berro, caja 74, carpeta 1. 
Montevideo en 1861, donde ejerció de jefe interino en 1863, época en que su padre dirigía el país. Participó en las fuerzas constitucionales contra los levantamientos revolucionarios comandados por Venancio Flores, hasta que este ocupó la jefatura del Estado uruguayo en marzo de 1865. Los enfrentamientos entre los llamados «colorados» y «blancos» (Partido Nacional) continuaron. En febrero de 1868, se produjo un fracasado intento revolucionario de estos últimos, siendo apresado y asesinado su padre. Mariano Berro se exilió entonces en la Argentina. Retornó al Uruguay acompañando al Partido Nacional en los alzamientos de $1870^{14}$. En 1875 fue electo diputado y entre 1877 y 1880 se desempeñó como jefe político del Departamento de Canelones, cargo desde el cual se interesó por promover la conservación de los montes, entre otras cuestiones ${ }^{15}$.

A partir de 1880 se dedicó a las actividades agropecuarias. Se radicó en el Departamento de Soriano, en la estancia de su esposa, Aurora Mercedes Chopitea, con quien se había casado en 1866 y tenido seis hijos. En la finca a orillas del arroyo Vera, un afluente del Rio Negro, se dedicó por 24 años a mejorar el ganado, importando progenitores de razas puras e introduciendo nuevas prácticas en los sistemas de crianzas. Complementó la dirección de estas actividades con el cultivo de árboles y otras plantas y la observación de la naturaleza. Paralelamente participó de comisiones locales de instrucción pública, actividades culturales y periodísticas ${ }^{16}$, escribiendo para periódicos locales y para revistas de Montevideo. También publicó algunas notas en la revista de la Asociación Rural del Uruguay, de la cual fue socio.

Berro se sumó al interés de los hacendados por cuestiones botánicas, tal como se manifestó en el ámbito de la Asociación Rural del Uruguay, sociedad creada en 1871. De hecho, esa asociación patrocinó en 1873, la publicación de una primera enumeración de la flora uruguaya confeccionada por el francés Ernesto Gibert (1818-1886), quien también formó un herbario, que heredaría uno de sus discípulos, el profesor español José Arechavaleta (1838-1912) ${ }^{17}$. Este último colaboraría con hacendados de la Asociación Rural en la determinación de especies de plantas y compartiría con algunos de ellos el interés por las herborizaciones y el estudio de las gramíneas, como se menciona más adelante en el caso de Berro. Anteriormente, otro miembro de la Asociación

${ }^{14}$ Idem.

15 Villegas Suarez, 1975: VI-VII.

16 Ibidem: XV.

17 Gibert coleccionó plantas en el Uruguay desde 1858 hasta su muerte en 1886, remitiendo ejemplares repetidos a Inglaterra y Alemania, para su clasificación. Una parte de sus colecciones sobreviviría en la Facultad de Medicina de Montevideo. Herter, 1928: 476. 
Rural y discípulo de Gilbert, Federico Balparda (1839-1888), había herborizado con Arechavaleta y confeccionando un herbario que fue premiado en la Exposición de Santiago de Chile de $1884^{18}$. En 1887, este hacendado al presentar una colección botánica donada por Arechavaleta a la Asociación Rural, señaló el interés de esta asociación por «conocer a ciencia cierta las numerosas variedades de gramíneas de nuestro suelo, ya que ellas forman en la alimentación de nuestros ganados la principal causa de sus rápidos engordes ${ }^{19}$.

Como otros ganaderos de la época, Berro se interesó por los vegetales que podían servir de forrajeras y prestó atención a la propagación de plantas foráneas invasoras, como el cardo negro que generó discusiones y experimentaciones entre propietarios de hacienda de ambas márgenes del Río de la Plata en la década de 1880. En 1888, se publicaron en los periódicos de Mercedes una serie de notas a favor y en contra de la utilidad del cardo negro ${ }^{20}$, una planta europea que por entonces se estaba propagando por el Uruguay y que anteriormente había generado unos debates similares entre miembros de la Sociedad Rural Argentina. Se consideraba que era una variedad oriunda de Escocia, cuyas semillas fueron introducidas por un criador inglés en Perú, y de ahí se propagó a Chile y luego a la Argentina, expandiéndose por los campos uruguayos a fines de la década de 1880. Berro consultó a algunos estancieros argentinos sobre el potencial de esa planta como forrajera, ya que algunos de ellos habían ensayado alimentar carneros con ese cardo unos años antes ${ }^{21}$. Asimismo, le comunicaron los estudios químicos efectuados en la Escuela de Veterinaria de Santa Catalina (Argentina), cuyos resultados indicaban que tenía una composición inofensiva y presentaba algunos elementos nutritivos para el ganado ${ }^{22}$. No obstante, las opiniones sobre esa planta en la Argentina seguían divididas, aunque el debate se había aplacado. A mediados de 1888, Berro publicó algunas notas en el diario La Reforma de Mercedes, señalando que podía utilizarse como forraje, según las

18 Arechavaleta, 1903: XLII.

19 Beretta Curi, 2012: 66-67

${ }^{20}$ Entre mayo y julio de 1888 se publicaron varios comentarios sobre el cardo negro en La Reforma, diario de Mercedes vinculado al Partido Nacional, y en La Cruzada, periódico del Partido Colorado en el Departamento de Soriano. La discusión fue iniciada por una nota de David M. Silveira (hijo), "El cardo negro no es venenoso", La Reforma, Mercedes, 24/5/1888: 1. En esa nota se insinuaba la utilidad de esa planta para alimentación del ganado.

${ }^{21}$ Sobre el cardo negro, Berro consultó a su cuñado Pastor Senillosa, a Mariano Acosta y a Felipe Amadeo, entre otros estancieros de Buenos Aires y miembros de la Sociedad Rural Argentina. Ciencias Naturales. Correspondencia con varias personas, 1888-1912, AGNU, Colecciones Particulares: Archivo de Mariano B. Berro, caja 82, carpeta 4.

${ }_{22}$ Carta de Felipe Amadeo a Mariano Berro, 18 de julio de 1888, AGNU, Colecciones Particulares: Archivo de Mariano B. Berro, caja 82, carpeta 4. 
observaciones de los ganaderos argentinos consultados ${ }^{23}$. Esto fue cuestionado desde la prensa opositora del Partido Colorado, considerando que aunque esa planta no tenía sustancias venenosas, las espinas perjudicaban los intestinos de los animales y era necesario exterminarla, ya que además, constituía una plaga para el agricultor ${ }^{24}$. Finalmente, el debate botánico pareció quedar inconcluso y teñido por los enfrentamientos políticos e ideológicos entre «blancos» y «colorados». En escritos posteriores, Berro seguiría considerando a esta planta como un buen forraje, al igual que otros cardos, que podía ser un recurso estacional en campos «malos», aunque no era deseable su propagación en buenas tierras ${ }^{25}$.

Este caso ilustra el interés de hacendados por cuestiones botánicas ligadas a los intereses rurales. Según se observa entre las cartas recibidas por Berro, otros dueños de campos, se dedicaron a identificar las plantas de sus terrenos y sus posibles aplicaciones o inconvenientes para las actividades agropecuarias. Por ejemplo, el argentino Enrique Lynch Arribálzaga, dedicado a estudios zoológicos, pero también coleccionista de la flora del Chaco, le comentaba:

\begin{abstract}
... aunque no soy botánico, me interesa también el conocimiento de la flora de los lugares donde resido y poseo felizmente suficientes nociones para distinguir muchas familias, bastantes géneros y algunas especies..., también he sido estanciero y labrador, y uno de las primeras curiosidades que tuve entonces fue reunir y clasificar todas las plantas del campo que ocupaba, con apuntes estadísticos y fenológicos... he reunido en el Chaco una pequeña colección de plantas, principalmente herbáceas, con varios ejemplares de cada especie y que, si Ud. lo deseara, me será muy grato remitirle uno de cada una, para enriquecer su herbario de comparación. No están envenenadas, ni tampoco muy bien arregladas ${ }^{26}$.
\end{abstract}

Como se examina más adelante, las muestras botánicas requerían una serie de tratamientos para su estabilización e incorporación a los herbarios, aunque sin esos procedimientos igual servían para afianzar lazos de reciprocidad entre los aficionados a los estudios de la naturaleza. Al igual que otros estancieros, Berro comenzó en su estancia a estudiar y coleccionar las gramíneas que podían servir de alimento al ganado. Su colección se fue enriqueciendo con otras plantas obtenidas por intercambios y excursiones por diversos ambientes y regiones. Asimismo, por cada espécimen recolectado buscó registrar el suelo donde crecía, la estacionalidad, los nombres vulgares, su

${ }^{23}$ Berro, Mariano, "Cuestiones rurales", La Reforma, 21/6/1888.

${ }^{24}$ Un Hacendado, "No más Cardo Negro", La Cruzada, Mercedes, 12/6/1888: 1-2. Simonelli, Luis, "Intereses Rurales", La Cruzada, 5/6/1888: 1-2.

25 Berro, 1900: 209.

26 Carta de Enrique Lynch Arribálzaga a Mariano Berro, 12 de enero de 1912, AGNU, Colecciones Particulares: Archivo de Mariano B. Berro, caja 74, carpeta 1. 
utilidad como forrajeras o para otras aplicaciones según los usos dados por pobladores locales ${ }^{27}$. También tuvo en cuenta algunas propiedades medicinales indicadas por curanderos indígenas. Paralelamente, coleccionó diversos documentos históricos vinculados al uso y cultivo de diversas plantas, la historia de la agricultura y de la introducción de árboles y otras especies extranjeras en su país. Al terminar el siglo XIX, la botánica se consideraba estrechamente ligada a la historia como se mencionó en el primer número de los Anales del Museo Nacional de Montevideo ${ }^{28}$. En sus publicaciones botánicas, Berro incluiría los nombres científicos y vulgares de cada especie y sus posibles empleos, esperando que esos trabajos fueran aprovechados por un amplio público no especializado en el lenguaje técnico de la ciencia.

A mediados de la década de 1890, Berro comenzó a dedicarse más intensamente a las ciencias naturales, retomando su afición de juventud. Siguiendo los pasos de su tío abuelo, registró en cuadernos las observaciones de animales y plantas que iba encontrando ${ }^{29}$. Sus observaciones zoológicas no fueron muy bienvenidas y recibieron algunas críticas del director del Museo Nacional de Buenos Aires, el zoólogo ruso-alemán Carlos Berg ${ }^{30}$, a quien terminaría donando sus colecciones entomológicas. Posteriormente, realizará algunas recolecciones de insectos a pedido de naturalistas de la Argentina. Al iniciarse el siglo XX, reconociendo la necesidad de una mayor especialización, se concentrará en la «botánica general» y en la formación de un herbario de la flora uruguaya. También se interesará por la agricultura colonial, la silvicultura y su historia en el Uruguay. Hacia 1912 participará en la promoción del día del árbol en su país y en la Argentina, difundiendo la iniciativa similar

27 Berro, 1906: 10.

${ }^{28}$ El abogado y político uruguayo Carlos María de Pena, también directivo de la Asociación Rural, reconocería la relación entre la botánica y la historia: «dígame Vd. Si no es interesantísimo para un botánico conocer la introducción de las plantas y sus transformaciones en nuestro suelo, que señalan al mismo tiempo las diferentes etapas de la civilización y de la historia del país. Diga Vd. si no es de la mayor importancia para un naturalista seguir paso á paso la invasión de plantas extranjeras que disputan el terreno á las indígenas, como ha sucedido con el diabólico cardo, más dominante, más colonizador que el mismo español que lo introdujo. Para el botánico y para el economista es utilísimo saber cuándo se introdujeron ciertas especies, cómo prosperaron y cuánto rindieron en su reproducción por la mano del hombre». Pena, 1894: XVI.

29 En el archivo de Berro, se conservan cuadernos, al estilo de los mantenidos por su tío Larrañaga, sobre distintos animales observados entre 1893 y 1917, consignando por cada especie su nombre científico y sus denominaciones vulgares, junto a detalles de su hábitat, hábitos y utilidad. Sobre los diarios de Larrañaga véase: Islas, 2015: XIX-XXXII.

${ }^{30}$ Correspondencia con Carlos Berg, AGNU, Colecciones Particulares: Archivo de Mariano B. Berro, caja 79, carpeta 21. 
que se daba en España y reenviando para allá las noticias sobre esta celebración en la región del Plata ${ }^{31}$. En ese sentido, como socio corresponsal de algunas asociaciones europeas se desempeñará como intermediario en la difusión de los trabajos y noticias botánicas en diferentes direcciones.

A partir de 1895, se presenta como «un entusiasta aficionado» ante naturalistas de la Argentina y luego de Europa. Con esta identidad, contrapuesta al del «sabio botánico», se continuará autodefiniéndose hasta su muerte ${ }^{32}$. No obstante, en la década de 1910 su nombre era conocido en los círculos botánicos. Sus colecciones, publicaciones y datos sobre la flora de la región de Soriano y luego del resto de Uruguay despertaron el interés de los botánicos de la otra orilla de la cuenca del Plata y también de Europa, donde sería incorporado como miembro de la Sociedad Botánica de Francia en $1906^{33}$, de la Sociedad Botánica de Ginebra en $1913^{34}$ y como socio corresponsal de la Sociedad Española de Amigos del Árbol desde 1912 ${ }^{35}$. Por entonces, no existía ninguna asociación dedicada específicamente a la botánica en Uruguay ni en la Argentina, aunque se incorporó como socio de sociedades naturalistas argentinas como la Sociedad Argentina de Ciencias Naturales, fundada en 1911, y la Sociedad Ornitológica del Plata creada en 1916, siendo además socio desde 1901

31 En 1912, el ingeniero español en montes, Ricardo Codorníu y Stárico, miembro fundador de la Sociedad Española de Amigos del Árbol y socio de la Sociedad Española de Historia Natural, le escribió a Berro invitándolo a ser socio corresponsal de la primera y a remitirles publicaciones y notas de interés para dicha sociedad. Asimismo, le ofrecía sus contactos con botánicos españoles. Berro aceptó el nombramiento, cumpliendo sus obligaciones como corresponsal. Entre 1912 y, por lo menos, 1917, Codorníu y Berro mantuvieron un asiduo intercambio epistolar, bibliográfico y de comentarios sobre repoblamiento forestal, fomento de vegetales útiles, organización de exposiciones y del Día del Árbol, entre otros temas botánicos, agrícolas y de la vida cotidiana. Correspondencia con la Sociedad Española de los Amigos del Arbol, AGNU, Colecciones Particulares: Archivo de Mariano B. Berro, caja 81, carpeta 3.

32 En 1915, por ejemplo, seguía declinando: «el honroso calificativo de sabio botánico, esto no por modestia sino porque no puede ser lo uno ni lo otro quien es solo amante del estudio y à quien una vida no siempre tranquila no le permitió frecuentar las aulas universitarias para recibir las enseñanzas que después debieran ser base sólida de los trabajos naturalistas. No soy pues sino un aficionado de las ciencias naturales, à que es cierto me dedico con cariño hace muchos años», Carta de Mariano Berro a Alberto Nin, 25 de enero de 1915, AGNU, Colecciones Particulares: Archivo de Mariano B. Berro, caja 79, carpeta 16.

33 Berro fue incorporado como socio en la sección del 14 de enero de 1906, Bulletin de la Société Botanique de France, LIII (París, 1906): 5.

${ }^{34}$ En la sesión del 13 de octubre de 1913 se aceptó su candidatura como socio, presentada por Gustave Beauverd y Teodoro Stuckert, Bulletin de la Société Botanique de Genève, V/7 (Ginebra, 1913): 245.

${ }_{35}$ Correspondencia con la Sociedad Española de los Amigos del Arbol, AGNU, Colecciones Particulares: Archivo de Mariano B. Berro, caja 81, carpeta 3. 
de la Sociedad Científica Argentina. Por otro lado, en 1907 se suscribió al libro de direcciones de botánicos del mundo (Botaniker Adressbuch) y a la sociedad de intercambios botánicos de Viena (Wiener Botanishe Tauschanstalt) ${ }^{36}$, para que incluyeran su nombre, presentándose como botánico colector, especializado en fanerógamas y poseedor de un herbario de plantas del Uruguay. El interés de Berro por la botánica se extendió por cerca de 25 años hasta poco antes de su muerte, el 26 de agosto de 1919. Su etapa más activa se dio tras retirarse de la administración de la estancia hacia 1898 y establecerse en Montevideo en 1902, y hasta cerca de 1917, cuando sus problemas de salud le dificultaban continuar con sus estudios predilectos. Por entonces, la guerra europea iniciada en agosto de 1914 había interrumpido sus contactos con científicos europeos y la compra de bibliografía y colecciones en Europa.

Este «entusiasta aficionado» recorrió diferentes regiones de su país para observar las distintas formaciones botánicas y recolectar muestras para confeccionar un herbario uruguayo «antes que nuestras especies desaparezcan con la agricultura y la ganadería, y dejar esos elementos reunidos para personas que me sucedan, que amen esta tierra y la ciencia» ${ }^{37}$. También reuniría ejemplares para intercambios y para complacer los pedidos de botánicos de otros países. Invirtió una considerable fortuna en la formación de una biblioteca sobre ciencias naturales e historia americana, a la que recurrirían en préstamo o través de consulta epistolar algunos botánicos de la Argentina y Uruguay. Sus publicaciones y notas periodísticas abarcaron varios temas: cuestiones de la administración pública, historia de la educación en el departamento de Soriano, propaganda anticlerical y críticas a posturas religiosas, notas sobre la vida rural y urbana, la flora y la historia de la agricultura en el territorio uruguayo. Sus principales trabajos botánicos fueron: «La vegetación uruguaya. Plantas que se hacen distinguir por alguna propiedad útil o perjudicial», publicado en los Anales del Museo Nacional (Montevideo, 1899) y otras obras editadas por su cuenta: Las gramíneas de Vera: enumeración, clasificación y utilización forrajera (1906, reimpreso en 1946) y La Agricultura Colonial $(1914 \text {, reeditado en } 1975)^{38}$.

36 Esta asociación se creó en 1845 y al terminar el siglo XIX era una de las más importantes sociedades de intercambio botánico, presentándose como espacio para intercambiar y comprar especímenes raros, así como para actuar de intermediaria en la venta de «bellas colecciones de plantas exóticas, especialmente aquellas que vienen de los trópicos». Sobre las sociedades de intercambio botánico en el siglo XIX, véase Robin, 2004: 49-71.

${ }^{37}$ Carta de Mariano Berro al profesor Juan A. Domínguez, 20 de octubre de 1906, AGNU, Colecciones Particulares: Archivo de Mariano B. Berro, caja 80, carpeta 3.

38 Berro, 1899; 1906; 1914. 
El archivo personal de Mariano B. Berro conservado en el Archivo General de la Nación (Uruguay), da cuenta de las actividades e intereses intelectuales de este coleccionista y aficionado a la botánica. Este fondo documental contiene más de 8000 piezas: cartas, cuadernos con anotaciones manuscritas y folletos producidos principalmente entre 1876 y 1919. Ello incluye los materiales vinculados con su actuación en la administración pública y en el movimiento liberal, las actividades agropecuarias, sus registros sobre temas históricos, familiares y la fauna y flora uruguaya, la correspondencia con amigos, coleccionistas, historiadores, escritores, naturalistas, instituciones científicas y editoriales, y recortes de diarios y anotaciones autobiográficas. Alrededor de un cuarto de esos documentos están clasificados como «ciencias naturales» y abarcan las cartas recibidas y borradores de las enviadas a botánicos, museos, asociaciones e instituciones botánicas y libreros de su país y de la Argentina, Francia, Suiza, Alemania, Austria, Dinamarca, Inglaterra y España (ver listado en el Anexo). También tuvo contactos en Chile, Paraguay y Brasil. En el último país, realizó recolecciones de plantas e interaccionó con varios naturalistas durante sus estadías invernales en Rio de Janeiro y otros lugares de Brasil. Como se examina a continuación, la organización del herbario, jugó un papel central en la mediación de esas interacciones e incluyó la conformación de una biblioteca especializada y de un archivo de la correspondencia enviada y recibida, donde quedaba el registro del número de cada planta remitida al exterior, según la numeración del herbario de Berro, y al cual posteriormente se agregaba el nombre científico determinado o corroborado por alguna autoridad botánica.

LA FORMACIÓN DEL HERBARIO Y LA CLASIFICACIÓN DE EJEMPLARES: SOCIABILIDAD E INTERCAMBIO

En la historia de la botánica se encuentra una forma peculiar de coleccionar especímenes: los herbarios. Tener un herbario y una biblioteca botánica asociada a la colección se consideró una base importante de conocimiento que complementaba, o aún ampliaba, la experiencia de primera mano con las plantas, obtenida a través de su cultivo o su observación en el campo. En su concepto moderno, la palabra herbario designa una colección de vegetales secos, prensados y preservados, cada uno montado en un pliego de papel o cartulina donde se agregan los datos de su recolección e identificación, y agrupados en carpetas y estanterías o gabinetes según las familias de plantas ${ }^{39}$.

39 Müller-Wille, 2006: 60-64. 
Como otro tipo de colección, reúne muchos especímenes en un espacio confinado y según un orden definido y $\operatorname{artificial}^{40}$. De forma semejante a otras colecciones biológicas, cada planta particular puede funcionar de dos formas: puede tomar el lugar de un espécimen típico de una especie y por lo tanto representar a ese taxón específico, o puede servir como una pieza de evidencia de la existencia de una especie o variedad en una región particular. Como señala Rheinberger, la planta de herbario puede volver a ser objeto de análisis directo, por lo tanto continúa permanentemente dispuesta como objeto epistémico potencial ${ }^{41}$. Para ello, las técnicas de preparación y preservación son fundamentales, permitiendo la continuidad de las muestras en el tiempo y su reclasificación. La hoja con el espécimen disecado puede ser entonces cambiada de lugar e ingresar en un nuevo orden taxonómico. Además, el herbario funciona como una colección abierta, donde es posible agregar nuevas hojas con fragmentos de la misma planta o de vegetales similares, los llamados «duplicados», que podían servir para futuras revisiones, análisis químicos, intercambios o donaciones. A diferencia de otras colecciones de historia natural, las muestras de vegetales secos eran objetos relativamente fáciles y económicamente mucho más baratos de enviar por correo y de reunir duplicados en el campo que otros materiales como fósiles, animales vertebrados o piezas arqueológicas.

La duplicación de muestras botánicas y su donación o intercambio se constituiría en un gesto fundamental en la sociabilidad botánica entre aficionados y especialistas ${ }^{42}$. Esto se observa en la correspondencia de Berro, quien siempre se negó a recibir dinero por sus muestras, ofreciéndolas «desinteresadamente» para iniciar los contactos con especialistas e instituciones científicas o como forma de retribuir las publicaciones recibidas o la ayuda en la clasificación de los ejemplares. Como señala Anne Secord, el rechazo a una bonificación monetaria por colecciones formó parte del código social del intercambio y de las relaciones de reciprocidad entre caballeros, mientras en otros casos los envíos de especímenes como obsequio o a cambio de información funcionaron como un medio de superar la distancia social entre corresponsales de diferentes clases sociales o con diferente formación o ubicación en el campo científico ${ }^{43}$.

Todas las plantas recolectadas para formar un herbario requerían un tratamiento de conservación y una revisión periódica de su estado, un saber prác-

\footnotetext{
${ }^{40}$ Keeney, 1992. Hoquet, 2016: 191-230.

${ }^{41}$ Rheinberger, 2007: 323.

42 Hoquet, 2016: 191-230. Robin, 2004: 49-71.

43 Secord, 1994: 393.
} 
tico que se adquiriría a través de los manuales para aficionados, la experimentación con diferentes elementos y los consejos de otros botánicos. En la década de 1910, Berro recordaría los problemas que encontraba un autodidacta al iniciarse en la práctica de herborizar:

En marzo de 1894, estando viviendo con mi esposa Aurora Chopitea de Berro y demás familia, en la Estancia Recuerdo, situada en Vera, departamento de Soriano, llevado de mi afición por el estudio de las ciencias naturales, resolví coleccionar las Gramíneas de Vera, estudiando tanto como elementos forrajeros, como adelanto de la ciencia botánica. Pronto conocí que las funciones de colectar eran mas difíciles de lo que parecía. Mis conocimientos como herborizador eran nulos, asì fue que mis fracasos en las primeras tentativas fueron completos. Las gramíneas que recogía se marchitaban, se les arrugaban las hojas, despedazaban y perdían el color. Al fin di con el servicio que podían dar los diarios, los libros, los colchones y toda clase de papel, con lo cual logré desecar pasablemente los ejemplares que iba recogiendo. Pude conseguir un tratado de botánica con algunas instrucciones de cómo se preparaban las plantas para herbario y esto me auxilio para ir adelante y para que los elementos de la colección fuesen mejorando $[\text { sic }]^{44}$.

Los manuales para aficionados y para la preparación de diferentes objetos de historia natural se fueron multiplicando a lo largo del siglo XIX y al terminar el siglo, las casas comerciales de historia natural de Paris, Viena o Berlín ofrecían a través de sus catálogos un amplio espectro de elementos y bibliografía para que coleccionistas con diferente formación y recursos iniciaran y completaran sus colecciones. La comercialización de estos objetos formó parte de un próspero mercado de materiales para museos, instituciones educativas, coleccionistas particulares y exhibiciones públicas. Esas empresas facilitaron la circulación de objetos en diversas direcciones así como la divulgación de prácticas científicas y de sistemas de clasificación y exposición. Esos emprendimientos comerciales también testimonian el crecimiento del consumo promovido alrededor del amor a la naturaleza y el estudio de la historia natura ${ }^{45}$. En la región del Plata, las editoriales y casas de historia natural francesas, seguidas por las alemanas, fueron los principales proveedores a los que recurrieron instituciones argentinas y uruguayas y coleccionistas como Berro.

A través de los catálogos de empresas parisinas como la casa Deyrolle ${ }^{46}$ y de agentes comerciales franceses, este aficionado comenzaría a adquirir los

44 "Catálogo de mis gramíneas", Estancia "Recuerdo”, Vera, Departamento de Soriano, 1913, AGNU, Colecciones Particulares: Archivo de Mariano B. Berro, caja 82, carpeta 11.

45 García y Podgorny, 2016: 27.

${ }^{46}$ La empresa Deyrolle tenía sus orígenes en un negocio de objetos de historia natural y taxidermia creado en 1831 por Jean-Baptiste Deyrolle y continuado por sus descendientes durante los siglos XIX y XX. Su nieto Emile comenzó a dirigirla hacia 1866, ampliando el nego- 
elementos para el trabajo botánico: papeles de estraza para disecar, cartones y tapas para herbarios, aparatos fotográficos, fichero y tarjetas para registro de las muestras y microscopios. También encargaría algunos pequeños herbarios, colecciones mineralógicas, obras generales y un manual para el naturalista, como la edición más reciente de Guide du naturaliste préparateur et du voyageur scientifique ou Instructions pour la recherche, la prépration, le transport et la conservation des animaux, vegetaux, mineraux, fossiles et organismos vivants. Este vademécum había sido escrito por un médico francés a partir de sus viajes a Turquía y ampliado en una segunda edición en 1883 por un ayudante naturalista del Museo de Historia Natural de Paris tras su experiencia en África tropical. Ofrecía indicaciones de como recolectar, preparar, acomodar, conservar y estudiar especímenes de los tres reinos de la naturaleza y materiales arqueológicos, recomendado asimismo el instrumental y otros elementos necesarios para cada tarea ${ }^{47}$. De esta forma, las recomendaciones para el «trabajo de campo» elaboradas a partir de la experiencia en Turquía sumada a la de África tropical se universalizaban en forma de manual y eran consumidas por aficionados de otras regiones y continentes como el estanciero del Departamento de Soriano en Uruguay.

Al iniciarse en su trabajo botánico, Berro se contactó con el director del Museo Nacional de Montevideo, José Arechavaleta, solicitando primero los Anales del Museo Nacional, que se empezaron a publicar en 1894 con trabajos dedicados a las gramíneas y otras familias botánicas del Uruguay escritos por Arechavaleta. Berro contó con su ayuda para «iniciarme en la operación de la determinación de las gramíneas y aun para transmitirme el nombre de los géneros de los ejemplares que le remitía» ${ }^{48}$. También realizaron juntos algunas excursiones y Arechavaleta lo invitó a publicar en los Anales del Museo Nacional, donde Berro publicó su primer trabajo botánico, el cual dedicó a su patrocinador. Sin embargo, las cordiales relaciones entre estos dos estudiosos de las gramíneas uruguayas se fueron deteriorando en los inicios

cio con la preparación de materiales para la educación científica y ofreciendo una diversidad de objetos, instrumentos y publicaciones para los interesados en la historia natural. Como se reconoció en la época, esta casa contribuyó en buena medida al fomento de la enseñanza de las ciencias naturales y de las actividades de aficionados. Sus catálogos comerciales circularon por ambas márgenes del Río de la Plata, siendo la principal proveedora de materiales de historia natural para el Museo Pedagógico de Montevideo y las instituciones escolares argentinas (García, 2015: 123). Berro comenzó solicitando a París colecciones de plantas, minerales, elementos para herbarios y bibliografía seleccionada a través de los catálogos de esta empresa.

${ }^{47}$ Capus, 1883.

48 "Catálogo de mis gramíneas", Estancia "Recuerdo", Vera, Departamento de Soriano, 1913, AGNU, Colecciones Particulares: Archivo de Mariano B. Berro, caja 82, carpeta 11. 
del siglo XX y Berro buscaría la ayuda de otros expertos para la clasificación de sus colecciones. En parte, dejó de remitirle ejemplares al director del Museo porque éste no le dedicaba su nombre a todas las nuevas especies que identificaba en sus herborizaciones ${ }^{49}$. El nombre científico a nueva planta era un reconocimiento esperado por los colectores botánicos. Arechavaleta solo le dedicó una nueva especie de gramínea (Chlaris Berroi) ${ }^{50}$, aunque encontró otras novedades entre las colecciones del estanciero de Soriano. En la Argentina, el botánico italiano Carlos Spegazzini bautizaría una especie en honor de Berro y posteriormente otros especialistas de Europa harían lo mismo a partir de los materiales enviados por ese «entusiasta aficionado» uruguayo.

Las cartas de otros botánicos muestran que los problemas de «rivalidad», «mezquindad científica» y el cese de colaboración entre estudiosos de las plantas se presentaban en otras instituciones y sectores de la región del Río de la Plata. Por ejemplo, el farmacéutico de origen suizo, Teodoro Stuckert, radicado en Córdoba (Argentina) y dueño de una estancia, le comentaba a Berro en 1900, su inicio en la botánica y sus actuales problemas para acceder a colecciones de comparación, la biblioteca y la ayuda del botánico de la Universidad de Córdoba:

Hace 5 ó 6 años he empezado à coleccionar yuyos, ayudándome al principio para la determinación y à mucho costo el D. F. Kurtz, catedrático de botánica de aquí, el que creyó después ver en mi su rival y de pura envidia trató de desprestigiarme. Esta desavenencia tuvo por resultado que hoy estoy privado de la opinión de un ilustre botánico, de la comparación de ejemplares del Museo botánico y de la biblioteca de la Universidad, de modo que para mis trabajos botánicos me encuentro completamente aislado aquí, atenido à mis propios recursos y esfuerzos, al lado de mi trabajo diario profesional. Las numerosas relaciones con Europa que frecuento, no me satisfacen por la demora en sus respuestas y los únicos que en algo me alientan y me aportaban son mis amigos Dr. C. Berg y Dr. C. Spegazzini à quienes tuve el gusto de conocerlos personalmente y tratarlos por numerosas cartas ${ }^{51}$.

49 A principios del siglo XX, Berro le comentaba a Stuckert que ya no quería pedirle ayuda a Arechavaleta, porque: «es muy grande egoísta, ni quiero tampoco confiarle la herborización, pues si hay ejemplares nuevos les encaja nombres de otros que nada han tenido que ver con ellos, como antes me hizo con varios hasta que dejé de ser zonzo, pues uno siempre tiene amor propio y desea dejar algún recuerdo de sus fatigas», Carta de Mariano Berro a Teodoro Stuckert, 8 de junio de 1908, AGNU, Colecciones Particulares: Archivo de Mariano B. Berro, caja 81, carpeta 11 .

${ }^{50}$ Villegas Suarez, 1975: VIII.

51 Carta de Teodoro Stuckert a Mariano Berro, 13 de enero de 1900, AGNU, Colecciones Particulares: Archivo de Mariano B. Berro, caja 81, carpeta 10. Al año siguiente, Stuckert volvía a mencionar sus dificultades para consultar los materiales de la Universidad Nacional de Córdoba: «Aquí en la Universidad en donde están las colecciones botánicas más valiosas del país, no me es dado utilizarlas, ni verlas, por causa que el Director es un individuo de 
La búsqueda de aliento, intercambio de opiniones y muestras, y asistencia en la identificación de ejemplares generará una amplia sociabilidad epistolar con personas de otras localidades y países. Esos intercambios, en muchos casos, se sostendrían por años, como la relación epistolar mantenida mensualmente entre Berro y Stuckert desde 1899 y hasta por lo menos 1918, gracias a la eficiencia de los servicios postales que permitían que en tres días llegaran las cartas y ejemplares botánicos entre Mercedes o Montevideo (Uruguay) y Córdoba (Argentina). La vinculación comenzó con tarjetas de presentación y envió de sus publicaciones y continuó con el intercambio de ejemplares, dibujos y fotografías, consultas sobre determinadas especies, noticias sobre los resultados de sus herborizaciones y ensayos de cultivo, opiniones sobre manuscritos en elaboración y préstamo de bibliografía. También las cartas incluyeron comentarios sobre sus vidas cotidianas, la administración de sus campos, los problemas familiares y económicos, las cuestiones políticas y las devastaciones causadas por las plagas de langostas, entre otros temas que preocupaban a estos dos estancieros-botánicos. Ambos compartieron su pasión por las plantas y el «trabajo desinteresado intelectual», así como la desgracia de haber perdido algunos hijos, encontrando un consuelo en la actividad científica.

Stuckert herborizó por distintas regiones de la Argentina y publicó numerosos trabajos sobre gramíneas argentinas y otras plantas. Organizó un herbario privado importante que estuvo disponible para la consulta de otros naturalistas, y que tras su muerte pasó a formar parte de las colecciones de la Universidad Nacional de Córdoba. También envió periódicamente colecciones a Europa y muestras a algunas instituciones de Estados Unidos, constituyendo un referente para conseguir plantas argentinas y al cual recurrirían la Sociedad Botánica de Francia, las universidades de Estocolmo, Estrasburgo, Ginebra y Nápoles, el Jardín Botánico de Kew e instituciones de Chicago, entre otras. Asimismo, mantuvo correspondencia con muchos botánicos sudamericanos y europeos, entre los que se contaban los principales especialistas en algunos grupos de plantas. Stuckert introdujo a Berro entre su círculo de contactos europeos, ejerciendo una especie de «magisterio en la distancia $»^{52}$. En ese sentido, le pasó fórmulas de envenenamiento de plantas e indicaciones para su conservación, así como las referencias de tratados botánicos para ordenar las colecciones, alentándolo a organizar su herbario: «una ocupación

primera clase, que no busca sino su nombre y su gloria». Carta de Teodoro Stuckert a Mariano Berro, 14 de junio de 1901, AGNU, Colecciones Particulares: Archivo de Mariano B. Berro, caja 81, carpeta 11.

52 Jesús Catalá-Gorgues (2018) menciona este concepto al analizar la relación epistolar entre dos entomólogos españoles. 
que hace pasar muy agradablemente las horas y es útil para la patria» ${ }^{53}$. El farmacéutico de Córdoba encontraba más grata esta tarea que el coleccionista uruguayo y para lo cual había desarrollado una metodología de trabajo que le permitía: «poner en orden en un término relativamente corto colecciones de 8-10000 ejemplares, que son las que yo generalmente compilo en un año de vegetación (sept-abril) $\rangle^{54}$.

La formación de un herbario involucró diferentes tareas y habilidades así como una distribución estacional de actividades. Por lo general, las excursiones y recolecciones de muestras o su cultivo se realizaban en primavera y verano, en marzo se secaban y envenenaban los ejemplares, y durante el invierno $^{55}$ se realizaban las trabajos de gabinete: ordenación de los ejemplares, etiquetado, catalogación en libros de entrada o fichas y la clasificación por familia botánica, insertando «lo nuevo entre lo viejo, es decir cada especie en la carpeta que pertenece ${ }^{56}$. Luego venia la tarea de identificar y corroborar el género y especie de cada ejemplar, una de las tareas más ardua para los aficionados como Berro más inclinado a las recolecciones y observaciones en el campo que a la determinación científica de los ejemplares y el arreglo del herbario, que como él mismo reconocía: «he descuidado mucho, por haber atendido mas à la herborización à que una fuerza irresistible me lanza y en el propio trabajo y fatigas encuentro goces; que alegría, que sensaciones que todo compensa cuando uno se encuentra con una planta desconocida» ${ }^{57}$.

53 Carta de Teodoro Stuckert a Mariano Berro, 9 de julio de 1903, AGNU, Colecciones Particulares: Archivo de Mariano B. Berro, caja 81, carpeta 10.

${ }^{54}$ Carta de Teodoro Stuckert a Mariano Berro, 23 de febrero de 1903, AGNU, Colecciones Particulares: Archivo de Mariano B. Berro, caja 81, carpeta 10. En otras cartas Sturckert comentaba sus métodos de trabajo y como registraba sus colecciones: «Llevo un libro de entradas, que cada especie recibe un numero (si son varias iguales el número será igual) con determinación aproximada, fecha y procedencia, etc. al lado izquierdo va un rotulo doblado con el mismo nombre $\mathrm{p}^{\mathrm{a}}$ poder leerlo por fuera, compilado por familias, con iguales rótulos por fuera... Asi arreglo colecciones voluminosas en un tiempo relativamente corto, pues poseo ahora de 3-400000 ejemplares en unas 600 carpetas». Carta de Teodoro Stuckert a Mariano Berro, 27 de agosto de 1908, AGNU, Colecciones Particulares: Archivo de Mariano B. Berro, caja 81, carpeta 11.

${ }_{55}$ Berro le comentaba a Carlos Porter, director del Museo de Valparaiso: «el acomodo de la colección de las Gramineas marcha con lentitud contra toda mi voluntad. Los trabajos de Gabinete los ejecuto siempre à fin de otoño è invierno ... ha de saber Ud. que tengo cumplidos 69 años y además soy solo en mis tareas y todo tiene que pasar por mis manos: coleccionar, secar, envenenar, catalogar, clasificar, etc.» Carta de Mariano Berro a Carlos Porter, 14 de febrero de 1908, AGNU, Colecciones Particulares: Archivo de Mariano B. Berro, caja 80, carpeta 19.

56 Carta de Teodoro Stuckert a Mariano Berro, 11 de marzo de 1907, AGNU, Colecciones Particulares: Archivo de Mariano B. Berro, caja 81, carpeta 11.

57 Carta de Mariano Berro a Teodoro Stuckert, 25 de diciembre de 1902, AGNU, Colecciones Particulares: Archivo de Mariano B. Berro, caja 81, carpeta 10. 
Se podría decir que Berro no fue un botánico de gabinete sino más bien un asiduo colector que disfrutaba de juntar «yuyos» y examinar las plantas en sus ambientes. Realizó excursiones por distintas regiones del Uruguay, aunque las guerras civiles y las devastaciones causadas por la langosta frenaron algunos años sus herborizaciones. Asimismo, se interesó por el cultivo de especímenes, ensayando la germinación de muchas de las muestras recibidas. En algunos inviernos, el arreglo del herbario quedo parado, por sus viajes a Brasil con su esposa, quien por prescripción médica necesitaba un clima más templado para su salud. En Río de Janeiro, Berro participaría de los círculos de sociabilidad científica de la capital brasileña y entraría en contacto con los naturalistas que recalaban en la travesía entre Buenos Aires y Europa. Además, aprovecharía para reunir muestras de la flora brasileña.

Al igual que otros naturalistas, para la determinación o confirmación del nombre científico de cada ejemplar enviaría muestras a alguna autoridad botánica. Mientras que los aficionados podían hacer observaciones y colecciones de la vegetación local e identificar las familias botánicas o aun el género de cada planta, para la determinación científica a nivel de especie se necesitaba la comparación de numerosos ejemplares y/o láminas así como un ojo entrenado y un saber especializado en cada grupo. Berro reconocía que las descripciones técnicas y las sinopsis no le bastaban para reconocer las especies de plantas, sumado a que algunos de esos textos estaban en latín. Además, el estado de la vista condicionaba las observaciones de microestructuras y las determinaciones de los ejemplares, generando un problema tanto a los aficionados como a los especialistas con más de medio siglo de vida, como se manifiestan en las cartas de Berro y algunos de sus corresponsales. Este coleccionista, por ejemplo, se quejaría de sus problemas visuales para la observación minuciosa de estructuras microscópicas a través de la lupa o el mi$\operatorname{croscopio}^{58}$, algo necesario para la identificación de algunas gramíneas. Esto sumado a su desconocimiento sobre algunos grupos botánicos y la falta de ilustraciones o material de comparación en otros casos, lo llevaron a aceptar

${ }^{58}$ En varias cartas a Stuckert, Berro le comentaba sus dificultades para arreglar el herbario, especialmente para identificar las especies de su colección, y para usar la lupa y el microscopio por la irritación que le causaban a la vista. En 1914, por ejemplo, mencionaba: «estoy entregado à una fuerte tarea, dando una mano à la revisación de mis plantas, pegándolas en papeles, colocándoles etiquetas, envenenando otras y determinando siempre que puedo pues me faltan elementos literarios para determinar à algunas y siempre carezco de muestras auténticas para comparar à otras. Todo esto lleva mucho tiempo y nunca queda uno conforme con su trabajo». Además agregaba que no podía usar el microscopio desde hacía «3 años pues me causa mucho daño y dolor a los ojos», Carta de Mariano Berro a Teodoro Stuckert, 3 de abril de 1914, AGNU, Colecciones Particulares: Archivo de Mariano B. Berro, caja 81, carpeta 11. 
la sugerencia de Stuckert de enviar colecciones de helechos y luego de otras plantas a Europa, a pesar de su desconfianza inicial hacia ese procedimiento:

... tengo coleccionado una cantidad de estas interesantes plantas, sin nombre aun las mas de ellas y Ud. me sugiere la idea de entregar los duplicados à algún especialista que me saque del pantano. Para el especialista habría la probabilidad de (...) nombrar à alguna planta nueva, de tener ejemplares de helechos americanos y en último caso de servir à la ciencia botánica. Sé de casos en que algunos señores de Europa reciben las plantas y luego se olvidan del remitente; pero esto es sin duda la escepcion. Si Ud. cree que el Sr. Dr H. Christ, ú otro en su lugar, de Basilea, le puede convenir recibir mi colección, estoy dispuesto à hacerlo, pero para eso seria necesario que que Ud. quisiera enviarme unas líneas para él de presentación ${ }^{59}$ (sic, subrayado original).

Junto con las cartas de presentación, Stuckert le daría recomendaciones de cómo manejarse en esas operaciones, no reclamando los ejemplares enviados y teniendo paciencia porque las remesas a Europa podían tardar más de un año en ser determinadas y algunos meses más en tener las respuestas. Además, le daría instrucciones de cómo enviar los helechos y la información que debía consignar con cada ejemplar para remitirle a Konrad H. Christ, una autoridad europea en ese grupo de plantas, además de «hombre millonario» y "de alta posición en el foro» de Basilea, la ciudad natal de Stuckert ${ }^{60}$. La transacción resultó de provecho para ambas partes. Christ acusó recibo de una excelente colección y lo estimuló a seguir trabajando ${ }^{61}$, mientras Berro obtuvo la determinación de las especies enviadas, con lo cual podía darles el nombre científico a los duplicados de su herbario. Los intercambios entre el especialista en helechos de Basilea y el aficionado de Montevideo se mantuvieron entre 1903 y 1912. Paralelamente, siguiendo las indicaciones y presentaciones del farmacéutico de Córdoba, Berro enviaría otros grupos de plantas para su determinación y entraría en contacto con importantes botánicos de la época que trabajaban de forma privada o vinculados a instituciones científicas tales como

59 Carta de Mariano Berro a Teodoro Stuckert, 9 de diciembre de 1902, AGNU, Colecciones Particulares: Archivo de Mariano B. Berro, caja 81, carpeta 10.

${ }^{60}$ Carta de Teodoro Stuckert a Mariano Berro, 13 de diciembre de 1902, AGNU, Colecciones Particulares: Archivo de Mariano B. Berro, caja 81, carpeta 10.

${ }^{61}$ Christ le agradeció ese primer envío de helechos de Uruguay, colección que le resultó muy interesante. Le trasmitió los resultados de las determinaciones, es decir los nombres científicos de los ejemplares enviados, y lo alentó a continuar en esa actividad: «vous voyez que cette collection renferme des espèces très intéressantes et je vous engage vivement de continuer vos études, je suis toujours prêt à vous renseigner sur les espèces ». Carta de Konrad Christ a Mariano Berro, 16 de mayo de 1903, AGNU, Colecciones Particulares: Archivo de Mariano B. Berro, caja 80, carpeta 1. 
el Jardín Botánico de Kew, el Museo Botánico de Copenhague, el Jardín y Museo Botánico de Berlín y el instituto privado Herbier Boissier de Ginebra. Entre ello, logró que uno de principales especialistas europeos en gramíneas sudamericanas, el austríaco Eduard Hackel, aunque ya retirado, aceptara la determinación de sus ejemplares. Los envíos de muestras e intercambios también abarcaron a naturalistas, ingenieros agrónomos y museos de Sudamérica, especialmente de la Argentina (ver listado en el Anexo). Su experiencia, biblioteca y colecciones se constituirían en una referencia importante para los ingenieros agrónomos y estudiosos de las plantas en su país y en las regiones vecinas.

A pesar de los riesgos de pérdidas o extravíos, el envío de ejemplares a cambios de determinaciones era uno de los mejores mecanismos para la organización de las colecciones botánicas con el nombre científico de cada muestra. De esta forma, el herbario se constituía como una tarea colectiva, donde un recolector en Córdoba podía contar con la determinación de ciertos tipos de plantas efectuadas en Tucumán, Berlín, Estocolmo, Múnich, entre otros lugares ${ }^{62}$. O un aficionado de Montevideo, disponer de los nombres científicos de sus colecciones gracias a las muestras enviadas a Buenos Aires, Córdoba, Londres, Basilea, Ginebra, Copenhague y París. Por otro lado, Berro reconocería en 1908 otro beneficio en la remisión de muestras a Europa:

Otra ventaja encuentro en el envio de plantas à Europa y es que si se pierden las que aquí me quedan, se salvaran aquellas. Aquí todo es anomal, y el amor à los estudios naturales es casi nulo, asi que para después de mi muerte no debo contar con mucho amor ni seguridad para mis colecciones: plantas, huesos fósiles y moluscos, piedras, objetos de indios indígenas, etc, etc. que es para pensarlo bien ${ }^{63}$.

En los inicios del siglo XX, el destino de las colecciones era una preocupación para varios coleccionistas del Río de la Plata, donde las instituciones estatales no se veían como un buen resguardo por la desorganización y pérdida de los objetos y la falta de inventarios, cuidados y científicos que los estudiaran. A lo que podían agregarse las desavenencias personales con los directores de los museos. En contrapartida, el envió de materiales a Europa corría el riesgo de que se extraviaran en el viaje o fueran retenidas mucho

62 Por ejemplo, Sturkert mencionaba: «mis Euforliáceas me las determinó el Dr. Lillo de Tucuman, las Acantáceas el Dr. G. Lindon de Berlin, las Asclepiadáceas por parte el Dr. G. Malme de Estokholmo, las Sapindáceas el Dr. Radhkafer de Munich», Carta de Teodoro Stuckert a Mariano Berro, 18 de junio de 1908, AGNU, Colecciones Particulares: Archivo de Mariano B. Berro, caja 81, carpeta 11.

${ }^{63}$ Carta de Mariano Berro a Teodoro Stuckert, 8 de junio de 1908, AGNU, Colecciones Particulares: Archivo de Mariano B. Berro, caja 81, carpeta 11. 
tiempo en las aduanas o, peor aún, quedaran olvidadas por los científicos o en los depósitos de las instituciones. Sin embargo, con la circulación de muestras se podían obtener determinaciones científicas más rápidas y avaladas por una autoridad científica. A su vez, formaba parte de los engranajes la sociabilidad científica y también era un mecanismo para generar amistades intelectuales. En el caso de Berro, aunque nunca viajó a Europa y solo visitó algunas ciudades de los países vecinos, a través de los envíos postales formó parte de las redes internacionales de la ciencia, que no solo implicaron relaciones norte-sur sino también sur-sur.

El estallido de la guerra en Europa a mediados de 1914 interrumpiría estos intercambios y la colaboración con los científicos del hemisferio norte ${ }^{64}$. En 1917, con los bloqueos y la presencia de barcos de guerra ingleses y alemanes en la entrada del Rio de la Plata, la navegación y las comunicaciones postales se dificultaron, generando un sentimiento de aislamiento del resto del mundo como experimentaría Berro. Por entonces, sus problemas de salud y sus «molestias espirituales» le dificultaban dedicarse a sus estudios predilectos:

... una de las causas que molesta mi espíritu tiene raíz en la guerra que hiere tan cruelmente à la Europa y aun puedo decir à todo el mundo. Mis relaciones con maestros en los ramos de algunas ciencias naturales va por tres años que se han ido cortando, y ahora por completo viéndome en el caso de lamentar tal desgracia. [...] Cada dia mas aislados con el resto del mundo pues los vapores van siendo muy contados y casi todas las noticias son recibidas por telégrafo. La actual guerra prueba que la humanidad carece de civilización ${ }^{65}$.

La Primera Guerra Mundial socavó los sueños de paz y amistad internacional promovidos por la ciencia y puso en cuestión la idea de «civilización» de las sociedades europeas. El impacto de la guerra en las distintas disciplinas científicas fue rotundo a nivel internacional no solo a raíz de las muertes y de la interrupción de los intercambios académicos, sino porque también puso de manifiesto la trama de las relaciones existentes entre las economías a escala mundial. Es por ello que una guerra, cuyo campo de batalla estaba a miles de kilómetros, repercutiría sobre diversos aspectos de la actividad científica de los países sudamericanos ${ }^{66}$. En ese contexto, el coleccionista de Montevideo ya no pensaría como una década antes que las instituciones europeas podían ser una salvación para sus colecciones. Finalmente su biblioteca y su herbario

${ }^{64}$ Carta de Mariano Berro a Ricardo Codorníu y Stárico, 2 de agosto de 1917, AGNU, Colecciones Particulares: Archivo de Mariano B. Berro, caja 81, carpeta 3.

${ }^{65}$ Carta de Mariano B. Berro a Ricardo Codorníu y Stárico, 2 de agosto de 1917, AGNU, Colecciones Particulares: Archivo de Mariano B. Berro, caja 81, carpeta 3.

${ }^{66}$ García y Podgorny, 2000. Ballesteros, Garcia y Podgorny, 2013. 
con cerca de 9000 ejemplares recolectados entre 1894 y 1916, quedarían bajo la custodia de un ingeniero agrónomo uruguayo, constituyendo las primeras colecciones del herbario de la Facultad de Agronomía de Montevideo ${ }^{67}$, donde aún se conservan.

\section{CONSIDERACIONES GENERALES}

En este trabajo se ha tratado la correspondencia del estanciero uruguayo Mariano B. Berro como un ejemplo para entender las complejidades de las redes científicas y la dinámica de intercambios y envíos de muestras, datos, publicaciones y estimulo entre aficionados y especialistas. Este caso permite observar los múltiples puntos y agentes que conformaron las redes «globales» de circulación de objetos e información, integrados por las rutas de navegación y el sistema postal hacia el 1900. Ello matiza ciertos tópicos de la historiografía sudamericana sobre la invisibilidad y el aislamiento de los naturalistas del cono sur, así como los relatos basados en un esquema unidireccional de centroperiferia. Al mismo tiempo, permite observar cómo los aficionados han sido mucho más que un ejército de manos colaboradoras, participando en la construcción y circulación del conocimiento a través de una vasta red descentralizada. Frecuentemente al estudiar la correspondencia científica, se ha focalizado en la institución o el científico famoso a donde confluyeron las colecciones y en cómo los científicos profesionales se han servido de sus corresponsales, pero poco se ha tenido en cuenta las motivaciones y prácticas de aquellos que les escribían. Sin embargo, la sociabilidad epistolar se mantenía en la medida en que los intereses de ambas partes se satisfacían. A su vez, las cartas revelan la trama biográfica y de intereses de los aficionados, configurando un espacio de formación e intersección con el mundo científico ${ }^{68}$. Además, permiten observar otros elementos que configuraron esas relaciones: las cuestiones de honor y los rasgos de estima, estímulo y consideración ${ }^{69}$.

En particular, el archivo de Berro muestra la continuidad entre las prácticas de observación y registro en las actividades rurales y el estudio de la botánica así como el interés de los estancieros por la identificación de la vegetación de sus campos, la experimentación de pastos que sirvieran para alimentación del ganado y la preocupación por la propagación de especies foráneas. Esto también llevaría, como se observa en el caso de Berro, a co-

\footnotetext{
67 Olivero, 2013: 165.

${ }^{68}$ Pupio, 2013: 33.

${ }^{69}$ Secord, 1994. Catalá-Gorgues, 2018.
} 
leccionar diversos documentos históricos y a indagar en la historia de la agricultura y de la introducción de diversas plantas extranjeras en su país. De esta forma, las prácticas e intereses de los aficionados muestran el cruce entre diversas disciplinas y entre actividades económicas e intelectuales.

La actuación de este rico coleccionista ilustra el devenir de un «apasionado aficionado» a las ciencias naturales y la dinámica de las prácticas naturalistas, donde la sociabilidad epistolar y los intercambios de objetos, información y publicaciones jugaron un papel fundamental. Su correspondencia muestra el carácter transaccional de esos intercambios, así como las conexiones locales y transnacionales a través de las cuales diferentes agentes definieron la transferencia de datos. El intercambio epistolar mantenido con botánicos de la Argentina y de varios países europeos, revela un amplio rango de intereses compartidos entre practicantes consagrados y otros menos eminentes y permite acceder a varios aspectos de la vida diaria de sectores centrales y marginales de la comunidad científica. Entre ello, se observa que las colecciones privadas (herbarios y bibliotecas) rivalizaban en contenido y en un acceso más público con los museos estatales de la región del Plata a fines del siglo XIX. En ese sentido, los botánicos, fuera del sistema académico, insistían en la naturaleza «desinteresada» de su trabajo científico frente a la producción científica realizada por investigadores asalariados preocupados por mantener su cargo en una institución. Además, considerarían que algunos hacían de las colecciones estatales un coto cerrado para mantenerse como encargado de las mismas, evitando estimular el trabajo de otros botánicos vistos como posibles competidores de su puesto institucional. Aficionados y botánicos que se mantuvieron al margen del movimiento de profesionalización de la ciencia persiguieron sus propias versiones de lo que debería ser la investigación de la naturaleza. Aunque sus motivaciones por la ciencia fueron variadas, las colecciones e información que reunieron pudieron intercambiarse, recopilarse y utilizarse para generar nuevos conocimientos, mostrando parte de los engranajes a través de las cuales sectores no académicos participaron en el flujo de datos y saberes científicos.

\section{Agradecimientos}

Este trabajo se basa en la documentación consultada en el Archivo General de la Nación en Montevideo, se agradece al personal de este acervo por la atención y las facilidades brindadas durante el relevamiento de esos materiales. 
Anexo: Correspondencia científica de Mariano B. Berro CON PERSONAS E INSTITUCIONES DEL EXTRANJERO, CONSERVADA EN EL Archivo General de la Nación, Uruguay

\begin{tabular}{|c|c|c|}
\hline País & Personas e instituciones & Años \\
\hline \multirow[t]{6}{*}{ Alemania } & Edward Rosenstock, horticultor y botánico de Gotha & 1908 \\
\hline & $\begin{array}{l}\text { Adolf Engler, director del Jardín Botánico de Berlín y responsable del } \\
\text { sistema taxonómico de clasificación de plantas que lleva su nombre }\end{array}$ & $1910-1911$ \\
\hline & Fritz Kränzlin, botánico de Berlín, especialista en orquídeas & 1910-1913 \\
\hline & Robert Pilger, miembro del Museo y Jardín Botánico de Berlín & 1911-1912 \\
\hline & $\begin{array}{l}\text { Alexander Nathansohn, profesor de botánica de la Universidad de } \\
\text { Leipzig }\end{array}$ & 1911 \\
\hline & Rudolf Schlachter, especialista en orquídeas de Berlín & 1913 \\
\hline \multirow[t]{17}{*}{ Argentina } & $\begin{array}{l}\text { Carlos Spegazzini, botánico italiano, jefe de laboratorio del Ministerio } \\
\text { de Agricultura, profesor en la Facultad de Agronomía de La Plata y en el } \\
\text { Museo de La Plata }\end{array}$ & $1895-1913$ \\
\hline & $\begin{array}{l}\text { Carlos Berg, zoólogo alemán, director del Museo Nacional de Historia } \\
\text { Natural de Buenos Aires }\end{array}$ & $1896-1900$ \\
\hline & $\begin{array}{l}\text { Teodoro Stuckert, farmacéutico de origen suizo, radicado en Córdoba y } \\
\text { dedicado a la botánica }\end{array}$ & $1899-1918$ \\
\hline & $\begin{array}{l}\text { Juan A. Domínguez, director del Museo Botánico de la Facultad de } \\
\text { Medicina de Buenos Aires }\end{array}$ & $1902-1914$ \\
\hline & $\begin{array}{l}\text { Alejandro Botto, ingeniero agrónomo y director de la Estación } \\
\text { Agronómica de la Facultad de Agronomía de La Plata }\end{array}$ & $\begin{array}{l}1899, \\
1916-1917\end{array}$ \\
\hline & Sociedad Científica Argentina & 1901-1919 \\
\hline & $\begin{array}{l}\text { Carlos Thays, paisajista francés, director del Jardín Botánico de Buenos } \\
\text { Aires }\end{array}$ & $1902-1905$ \\
\hline & $\begin{array}{l}\text { Eugenio Autran, botánico suizo arribado a la Argentina en los inicios } \\
\text { del siglo XX, empleado en el Ministerio de Agricultura y luego en el } \\
\text { Museo Botánico de la Facultad de Medicina de Buenos Aires. } \\
\end{array}$ & $1902-1908$ \\
\hline & Museo Nacional de Historia Natural de Buenos Aires & 1903-1917 \\
\hline & $\begin{array}{l}\text { Nicolás Rojas Acosta, maestro y director del Museo Provincial de } \\
\text { Corrientes }\end{array}$ & $1904-1915$ \\
\hline & Ministerio de Agricultura de la Nación & 1909-1919 \\
\hline & $\begin{array}{l}\text { Augusto Scala, profesor de botánica y encargado de la Sección de } \\
\text { Botánica del Museo de La Plata }\end{array}$ & 1909-1919 \\
\hline & \begin{tabular}{|l|} 
Luis María Torres, arqueólogo del Museo de La Plata y director de la \\
Sección de Historia de la Facultad de Filosofía y Letras de Buenos Aires \\
\end{tabular} & $1909-1913$ \\
\hline & $\begin{array}{l}\text { Clemente Onelli, naturalista italiano, director del Jardín Zoológico de } \\
\text { Buenos Aires }\end{array}$ & $1910-1919$ \\
\hline & $\begin{array}{l}\text { Enrique Lynch Arribálzaga, zoólogo instalado en Resistencia (Chaco), } \\
\text { vinculado a la Dirección general de Defensa Agrícola del Ministerio de } \\
\text { Agricultura y varias asociaciones científicas }\end{array}$ & $1911-1915$ \\
\hline & Sociedad Forestal Argentina & 1911-1917 \\
\hline & Sociedad Rural de la Pampa & $1912-1916$ \\
\hline
\end{tabular}




\begin{tabular}{|c|c|c|}
\hline País & Personas e instituciones & Años \\
\hline \multirow[t]{8}{*}{ Argentina } & $\begin{array}{l}\text { Felipe G. Senillosa, abogado, estanciero, sobrino político de Berro, } \\
\text { directivo de la Sociedad Rural Argentina y luego de la Sociedad Rural } \\
\text { de la Pampa. Director general de Agricultura y Defensa Agrícola del } \\
\text { Ministerio de Agricultura entre } 1916 \text { y } 1920\end{array}$ & 1914-1918 \\
\hline & $\begin{array}{l}\text { León Denis, estanciero de origen belga y aficionado botánico, } \\
\text { propietario de yerbales en el territorio misionero y colaborador del } \\
\text { Ministerio de Agronomía de la Argentina. }\end{array}$ & 1914 \\
\hline & Instituto Geográfico Argentino & 1915 \\
\hline & $\begin{array}{l}\text { Miguel Lillo, naturalista de Tucumán, formó importantes colecciones } \\
\text { del noroeste argentino }\end{array}$ & 1917 \\
\hline & Sociedad Argentina de Ciencias Naturales & 1917-1919 \\
\hline & $\begin{array}{l}\text { Cristóbal Hicken, botánico, profesor universitario y director del } \\
\text { Instituto privado Darwinion }\end{array}$ & 1918-1919 \\
\hline & Sociedad Ornitológica del Plata & 1918-1919 \\
\hline & Lorenzo Parodi, ingeniero agrónomo & $1917-1919$ \\
\hline Austria & Eduard Hackel, botánico, especialista en gramíneas sudamericanas & 1908-1913 \\
\hline Chile & Carlos Porter, director del Museo de Valparaíso & 1908 \\
\hline \multirow[t]{3}{*}{ Dinamarca } & $\begin{array}{l}\text { Eugenius Warming, director del Jardín Botánico de la Universidad de } \\
\text { Copenhague hasta } 1910\end{array}$ & $1897-1910$ \\
\hline & $\begin{array}{l}\text { Carl F.A. Christensen, botánico danés, especialista en helechos } \\
\text { y superintendente del Museo Botánico del Jardín Botánico de la } \\
\text { Universidad de Copenhague }\end{array}$ & $1908-1913$ \\
\hline & $\begin{array}{l}\text { Carl Emil Hansen Ostenfeld, curador del Museo Botánico de la } \\
\text { Universidad de Copenhague. }\end{array}$ & $1910-1912$ \\
\hline España & $\begin{array}{l}\text { Ricardo Codorníu y Stárico, ingeniero de montes y presidente de la } \\
\text { Sociedad Española de los Amigos del Arbol }\end{array}$ & $1912-1917$ \\
\hline Finlandia & Karl Evald Hamilkar Odenwall, terrateniente y botánico & $1909-1910$ \\
\hline \multirow[t]{2}{*}{ Francia } & Sociedad Botánica de Francia & 1905-1918 \\
\hline & $\begin{array}{l}\text { Jean Baptiste Gèse, ingeniero agrónomo de Villefranche de Rouergue, } \\
\text { Aveyron }\end{array}$ & $1910-1917$ \\
\hline \multirow[t]{3}{*}{ Inglaterra } & Charles B. Clarke, botánico del Jardín Botánico de Kew & 1904 \\
\hline & $\begin{array}{l}\text { David Prain, botánico escoses, director del Jardín Botánico de Kew } \\
\text { entre } 1905 \text { y } 1922 .\end{array}$ & 1914-1915 \\
\hline & $\begin{array}{l}\text { Whitehall Gardens, Londres (pedido de semillas e información para el } \\
\text { Conservador de Bosques de Sierra Leona, África) }\end{array}$ & 1914 \\
\hline Paraguay & $\begin{array}{l}\text { Serafin Rivas Rodríguez, médico español aficionado a las ciencias y a } \\
\text { la masonería. Vivió } 30 \text { años en Mercedes, Departamento de Soriano } \\
\text { (Uruguay). Entre } 1888 \text { y } 1897 \text { residió en Paraguay y luego regresó a } \\
\text { Uruguay, manteniendo el contacto con Mariano B. Berro }\end{array}$ & 1895 \\
\hline \multirow[t]{4}{*}{ Suiza } & $\begin{array}{l}\text { Konrad Hermann Heinrach Christ, jurista y naturalista de Basilea, } \\
\text { especialista en helechos }\end{array}$ & $1903-1912$ \\
\hline & $\begin{array}{l}\text { Casimir de Candolle, dedicado a las fanerógamas, continuó la tradición } \\
\text { familiar por la botánica y el enriquecimiento del herbario }\end{array}$ & $1908-1910$ \\
\hline & $\begin{array}{l}\text { Gustave Beauverd, conservador del Herbario privado Boissier, } \\
\text { Chambesy }\end{array}$ & 1900-1918, \\
\hline & Sociedad Botánica de Ginebra & 1909-1918 \\
\hline
\end{tabular}




\section{BIBLIOGRAFÍA}

Arechavaleta, José, "Flora Uruguaya. Tomo II", Anales del Museo Nacional de Montevideo, V (Montevideo, 1903): I-160.

Ballesteros, Diego, García, Susana y Podgorny, Irina, "Propaganda and cultural reconquest: The German scientific associations and the impact of the Great War on the sciences, Argentina, 1914-1930", Maria Fernanda Rollo, Ana Pardo Pires y Noémia Malva Novais (eds.) War and propaganda in the XXth Century, Lisboa, Universidade Nova de Lisboa, 2013: 104-110.

Beauverd, Gustave, “Contribution à l'étude des Composées", Bulletin de la Société Botanique de Genève, V (Ginebra, 1913): 205-228.

Beretta Curi, Alcides, "Elite, agricultura y modernización: el programa de la Asociación Rural del Uruguay, 1870-1900", Alcides Beretta Curi (org.) Agricultura y modernización 1840-1930, Montevideo, Ediciones Universitarias / CSIC, 2012: 43-89.

Berro, Mariano B., "La vegetación uruguaya. Plantas que se hacen distinguir por alguna propiedad útil o perjudicial", Anales del Museo Nacional, II (Montevideo, 1899): 89-196.

Berro, Mariano B., Ciudad y Campo, Montevideo, Dornaleche y Reyes, 1900.

Berro, Mariano B., Las gramíneas de Vera. Enumeración, clasificación y utilización forrajera, Montevideo, Imprenta artística, 1906.

Berro, Mariano B., La agricultura colonial, Montevideo, Imprenta Artística de Juan J. Dornaleche, 1914.

Capus, Guillaume, Guide du naturaliste préparateur et du voyageur scientifique ou Instructions pour la recherche, la préparation, le transport et la conservation des animaux, végétaux, minéraux, fossiles et organismes vivants et pour les études histologiques et anthropologiques (2e édition entièrement refondue), París, J. B. Baillière et fils, 1883.

Catalá-Gorgues, Jesús I., "Un magisterio en la distancia: la relación epistolar entre los entomólogos José María Dusmet y Modesto Quilis", Asclepio. Revista de Historia de la Medicina y de la Ciencia, LXX/1 (Madrid, 2018): 214-230.

Charvolin, Florian, Micoud, Andre y Nyhart, Lynnk (eds.), Des Sciences citoyennes? La Question de l'amateur dans les sciences naturalistes, La Tour d'Aigues, Editions de l'Aube, 2007.

Corsi, Pietro, The Age of Lamarck: Evolutionary Theories in France, 1970-1983, Berkeley, The University of California Press, 1988.

Di Stefano, Roberto, “Colegas Clérigos del joven Darwin”, Anuario IEHS, XXV (Tandil, 2010): 259-280.

García, Susana V., "La industria didáctica y las colecciones escolares en perspectiva histórica", Marcela Pelada (comp.), Patrimonio histórico educativo. Investigacio- 
nes y experiencias en América Latina y Península Ibérica, Buenos Aires, Huellas de la Escuela, 2015: 119-134. https://issuu.com/huellasdelaescuela/docs/ simposio230_4b6b2ae2c79379

García, Susana V. y Podgorny, Irina, "El sabio tiene una patria. La primera Guerra mundial y la comunidad científica argentina", Ciencia Hoy, X/55 (Buenos Aires, 2000): 24-34.

García, Susana V. y Podgorny, Irina, "El museo en los tiempos de la historia natural. Colecciones y universidad alrededor de 1900", Códice. Boletín científico y cultural del Museo Universitario, Universidad de Antioquia, XVII/29 (Medellín, 2016): 8-29.

Herter, Guillermo, "Las plantas uruguayas de Ernesto Gibert. Nomenclatura gibertianus", Anales de la Universidad, XXXVII/128 (Montevideo, 1928): 473-570.

Hoquet, Thierry, "What Does It Mean to be Central? A Botanical Geography of Paris 1830-1848", Journal of the History of Biology, XLIX/1 (Boston, 2016): 191-230.

Islas, Ariadna, "Prólogo", Dámaso A Larrañaga, Diario de Historia Natural 18081814, Montevideo, Biblioteca Artigas del Ministerio de Educación y Cultura. 2015: VII-XXXII.

Keeney, Elizabeth, The Botanizers: Amateur Scientists in Nineteenth-Century America, Chapel Hill, University of North Carolina Press, 1992.

Klemun, Marianne, "Introduction: «Moved» natural objects - «spaces in between»", HOST-Journal of History of Science and Technology, V (Lisboa: 2012): 7-16.

Kohler, Robert, "Finders, Keepers: Collecting Sciences and Collecting Practice", History of Science, XLV/4 (Londres, 2007): 428-454.

Lopes, Maria Margaret y Heizer, Alda, "Bompland, Saint-Hilaire e o Megatherium nas coleçôes de cartas de Dámaso Antonio Larrañaga (1771-1848)", Maria Margaret Lopes y Alda Heizer (eds.), Colecionismos, práticas de campo e representações, Campina Grande, EDUEPB, 2011: 11-23.

Malme, Gustave, "Asclepidaceae uruguayenses a clarissimo B. Berro collectae", Bulletin de la Société Botanique de Genève, VII/8 (Ginebra: 1911): 268-274.

Müller-Wille, Staffan, "'Linnaeus' herbarium cabinet: a piece of furniture and its function”, Endeavour, XXX/2 (Amsterdam, 2006): 60-64.

Olivero, Roberto, El edificio central de la Facultad de Agronomía, testigo centenario de una historia, Montevideo, Ediciones Universitarias / CSIC, 2013.

Osorio, Hector, "Contribution to the lichen flora of Uruguay XVI. Lichens collected by Mariano B. Berro", Phytologia, XLVII/5 (Nueva York, 1981): 393-396.

Pena, Carlos Maria de, "Por vía de introducción", Anales del Museo Nacional de Montevideo, I/1 (Montevideo, 1894): VI-XLVII.

Podgorny, Irina, "Mercaderes del pasado: Teodoro Vilardebó, Pedro de Angelis y el comercio de huesos y documentos en el Río de la Plata, 1830-1850", Circumscribere: International Journal for the History of Science, IX (San Pablo, 2011): 29-77. 
Pupio, María Alejandra, "Archivos para una historia de la práctica de la arqueología", Revista Electrónica de Fuentes y Archivos, IV/4 (Córdoba, Argentina, 2013): 24-33.

Rheinberger, Hans-Jörg, "Preparaciones: «Representaciones» de sí mismas”, Edna Suárez Díaz (ed.), Variedad infinita: ciencia y representación. Un enfoque histórico, México D.F., Limusa, 2007: 319-333.

Roberts, Lissa, "Situating Science in Global History: Local Exchanges and Networks of Circulation", Itinerario, XXXIII/1 (Cambridge, 2009): 9-30.

Robin, Nicolas, "Eléments pour une histoire culturelle de la botanique moderne. Les sociétés d'échanges de plantes en Europe de l'Est au dix-neuvième siècle", Archives Internationales d'Histoire des Sciences, LIV/152 (Turnhout, 2004): 49-71.

Schaffer, Simon, Roberts, Lissa, Raj, Kapil y Delbourgo, James, The Brokered World: Go-betweens and Global Intelligence, 1770-1820, Uppsala, Science History Publications, 2009.

Secord, Anne, "Corresponding interests: Artisans and gentlemen in nineteenth-century Natural History", British Journal for the History of Science, XXVII/4 (Londres, 1994): 383-408.

Stebbins, Robert, "Avocational science: The Amateur routine in Archaeology and Astronomy”, International Journal of Comparative Sociology, XXI/1 (Leiden, 1980): 34-48.

Villegas Suarez, Ernesto, "Prólogo", Mariano Berro, La Agricultura Colonial, Montevideo, Ministerio de Educación y Cultura, 1975: IX-XLIV.

Fecha de recepción: 21 de junio de 2019.

Fecha de aceptación: 26 de diciembre de 2019.

Epistolary sociability in the practices of amateur naturalists: the case of Uruguay's Mariano B. Berro (1838-1919)

This paper examines aspects of the activities of amateur naturalists in South America, focusing on the correspondence and botanical practices of Mariano Balbino Berro, a Uruguayan landowner who become an "amateur enthusiast" of the study of local nature. His case illustrates the dynamics of the circulation networks of samples and information between amateurs and specialists in South America and Europe in the transition from the nineteenth to twentieth centuries.

KeY woRDs: amateurs; botany; Uruguay; Argentina; correspondence networks. 
